\title{
COMPARISON IN MECHANICAL PROPERTIES OF ZIRCONIUM TITANATE (ZrTIO4) SYNTHETIZED BY ALTERNATIVE ROUTES AND SINTERED BY MICROWAVE (MW)
}

\author{
R. Guillén ${ }^{1}$, A. Borrell ${ }^{1}$, M. Salvador ${ }^{1}$, F. L. Penaranda-Foix ${ }^{2}$, R. Moreno ${ }^{3}$ \\ ${ }^{1}$ Instituto de Tecnología de Materiales (ITM), Universitat Politècnica de València, Camino \\ de Vera s/n 46022, Valencia, Spain \\ ${ }^{2}$ Instituto de Aplicaciones de las Tecnologías de la Información y de las Comunicaciones \\ Avanzadas (ITACA), Universitat Politècnica de València, Camino de Vera s/n, 46022, \\ Valencia, Spain \\ ${ }^{3}$ Instituto de Cerámica y Vidrio, CSIC, Kelsen 528049 Madrid, Spain \\ reguipi@upv.es
}

Keywords: Microwave sintering, Synthesis methods, Mechanical properties

\begin{abstract}
This paper shows the mechanical properties of zirconium titanate $\left(\mathrm{ZrTiO}_{4}\right)$ synthetized by SOL-GEL and Lyophilization methods. In bout cases, the materials were fabricated to different sintering method: Microwave and Conventional. The sinterization parameter for conventional were $1500^{\circ} \mathrm{C} / 2 \mathrm{~h}$ and for microwave $1200^{\circ} \mathrm{C} / 10 \mathrm{~min}$. The material obtained was characterized by micro-indentation technique and FESEM analysis of microstructure. It was observed that the microwave sintering process produce comparable density and uniform microstructure with conventional, using less time and energy.
\end{abstract}

\section{Introduction}

At present, $\mathrm{ZrTiO}_{4}$ nanopowders are used as a dielectric material in the electroceramic field, applications of catalysis, microwave telecommunications devices, pigments, composites, etc. One of the most interesting applications is the potential as structural material and similar applications that require a high thermal resistance. However, all the properties of zirconium titanate are still a subject of interest for the industrial field.[1][2]

There are several routes of synthesis of $\mathrm{ZrTiO}_{4}$; among them is the sol-gel method and lyophilization. These methods have been used to make powders or small pieces of zirconium titanate. However, structural applications require materials in large quantities, so it is necessary to identify the differences between the methods of synthesizing and allowing the preparation of powders suitable for the generation of green materials for subsequent sintering process.[3]

To develop a new generation of nanomaterials with microstructural differences it is necessary to innovate in the sintering process. Years ago, the use of conventional oven for sintering material was the usual procedure. Nowadays, non-conventional methods as Microwave sintering (MW) are a bright way to produce high dense materials, using heating rates in reduce dwell times and lower consumption using 70\%-80\% less energy[4]. 
This reactive sintering technique achieves excellent mechanical properties, homogeneous microstructure employing lower sintering temperatures. All these energy and economic advantages generate a new vision for the future on ceramic materials and their industrial production.

The main objective of this study is investigated and compacted of the mechanical properties of the materials synthesized by sol-gel method and lyophilization and sintered by microwave and conventional processes.

\section{Materials and experimental procedure}

\subsection{Material}

Commercial undoped m-ZrO 2 (TZ-0, Tosoh Tokyo, Japan) and anatase- $\mathrm{TiO}_{2}$ (Aeroxide $\mathrm{P} 25$, Degussa, Germany) were used as starting powders to obtain $\mathrm{ZrTiO}_{4}$ materials. Starting zirconia and anatase powders have average particle diameters of $300 \mathrm{~nm}$ and $40 \mathrm{~nm}$, and specific surface areas of $14 \mathrm{~m}^{2} \mathrm{~g}^{-1}$ and $52 \mathrm{~m}^{2} \mathrm{~g}^{-1}$, respectively. The approach used involves the preparation of a total solids loading suspension of 30 vol. $\%$, with 15 vol. $\%$ of $\mathrm{m}-\mathrm{ZrO}_{2}$ and 15 vol.\% of a- $\mathrm{TiO}_{2}$, using a poly(acrylic acid) based polyelectrolyte (Duramax D3005 Rohm and Haas, USA) as a dispersant to a total concentration of $5.2 \mathrm{wt} . \%$ on a dry solids basis. This high content of deflocculant is due to the nanometric size of titania that can be effectively dispersed with a concentration of $4 \mathrm{wt} . \%$ as demonstrated in previous work [5].

\subsection{Powder mixture preparation}

For the preparation of the materials, $\mathrm{m}-\mathrm{ZrO}_{2}$ powders were firstly added to the proper amount of distilled water containing the dispersant with the help of a high shear mixer (L2R, Silverson, Chesham, UK). Afterwards a- $\mathrm{TiO}_{2}$ nanopowders were dispersed with the help of the high shear mixer and an ultrasonic probe (UP 400 S, Hielscher, Stuttgart, Germany). Sonication was performed using several cycles of $1 \mathrm{~min}$, being the maximum sonication time of $8 \mathrm{~min}$ and a frequency of $24 \mathrm{kHz}$, since further sonication cycles led to reagglomeration. The final suspension was frozen in a liquid nitrogen bath and then dried in a freeze drier (Cryodos-50, Telstar, Spain) for $24 \mathrm{~h}$. Powders obtained were sieved using a $37 \mu \mathrm{m}$ mesh nylon sieve before sintering.

\section{3 $\mathrm{ZrTiO}_{4}$ powders sintering}

The material was sintered by conventional (CS) in an electrical furnace at $1500{ }^{\circ} \mathrm{C}$ with a heating rate of $10{ }^{\circ} \mathrm{C} / \mathrm{min}, 2$ and 6 hours of dwelling time at the maximum temperature. Microwave (MW) sintering at $1200{ }^{\circ} \mathrm{C}$ with a heating rate of $100{ }^{\circ} \mathrm{C} / \mathrm{min}$ and $15 \mathrm{~min}$ dwelling time at the maximum temperature. These selected parameters are based on previous studies in our research group, where sintering conditions were optimized for Y-TZP materials [6].

\subsection{Material Characterization}

Sintered density and open porosity were determined by the Archimedes' method, introducing the samples into water according to the ASTM C373-88. At the same time, Mechanical properties were evaluated on surfaces polished down to one $\mu \mathrm{m}$ using diamond paste. Hardness $(\mathrm{H})$ was evaluated via the micro indentation technique.

Specimen microstructures were characterised by means of field emission-scanning electron microscopy (FE-SEM, Gemini Ultra 55 model, Zeiss). A 30 minutes thermal etching was performed at $100{ }^{\circ} \mathrm{C}$ below the maximum temperature to reveal grain boundaries. The linear 
intercept method was used to measure the average grain sizes of material [7]. Approximately 100 grains were considered for each phase.

\section{Results and discussion}

The density values for all samples sintered via microwave (MW) and conventional sintering (CS) are shown in the Table 1. In a general view, the results show that the sintering processes by MW and CS at different temperatures and dwell times have values of densification around 90-100\%.

\section{Table 1}

Sintering conditions, density and grain size values of $\mathrm{ZrTiO}_{4}$ sintered under different microwave and conventional conditions.

\begin{tabular}{|c|c|c|c|c|c|}
\hline Material & $\begin{array}{c}\text { Sintering } \\
\text { method }\end{array}$ & $\begin{array}{c}\text { Temperature } \\
\left({ }^{\circ} \mathrm{C}\right)\end{array}$ & $\begin{array}{l}\text { Dwell } \\
\text { time } \\
\text { (min) }\end{array}$ & $\begin{array}{c}\text { Density } \\
\text { (\%) }\end{array}$ & $\begin{array}{c}\text { Grain } \\
\text { size } \\
(\mu \mathrm{m})\end{array}$ \\
\hline \multirow{3}{*}{$\begin{array}{c}\mathrm{ZrTiO}_{4} \\
\text { (Sol Gel) }\end{array}$} & \multirow{2}{*}{$\mathrm{CS}$} & 1500 & 120 & 98.0 & 1.95 \\
\hline & & 1500 & 360 & 98.9 & 2.26 \\
\hline & MW & 1200 & 15 & 99.7 & 1.00 \\
\hline \multirow{3}{*}{$\begin{array}{c}\mathrm{ZrTiO}_{4} \\
\text { (Lyophilized) }\end{array}$} & \multirow[t]{2}{*}{$\mathrm{CS}$} & 1500 & 120 & 85.5 & 1.64 \\
\hline & & 1500 & 360 & 93.3 & 1.33 \\
\hline & MW & 1200 & 15 & 95.1 & 1.00 \\
\hline
\end{tabular}

The density of the material $\mathrm{ZrTiO} 4$ synthetized by Sol-Gel method represent the higher values in compare with Lyophilized. In the same way, the result of hardness indicates that Sol-gel material is superior. Even though, dwell time influence in their performance. For example, the sol-gel materials sintered by CS displays that with more exposure of dwell time the hardness value decrease (Figure 1). Conversely, the Lyophilized material rise the hardness value with more exposure of dwell time. 


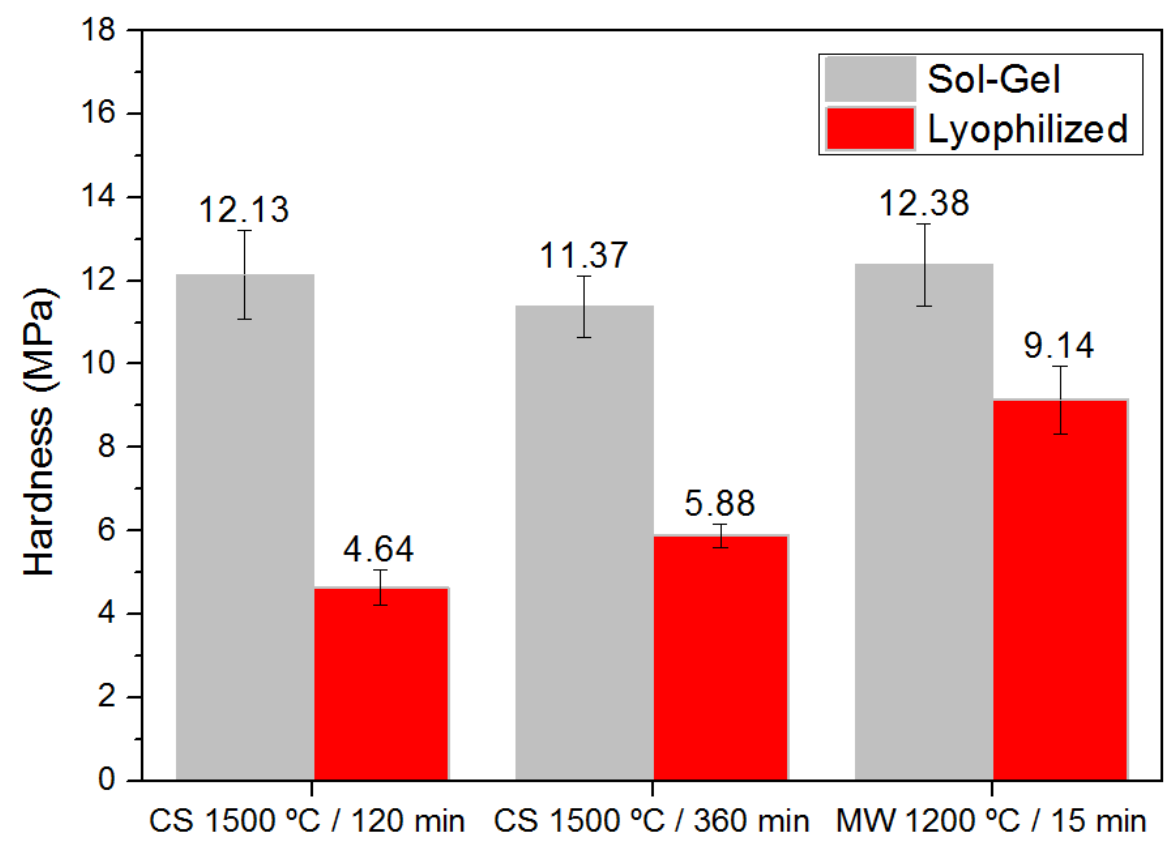

Figure 1. Hardness evaluation of $\mathrm{ZrTiO} 4$ materials.

Subsequently, is important to emphasize the behavior of each material base on the sintering method. Both materials display an improvement in the physical properties. Density and harness grown significantly by microwave sintering method.

Figure 2 shows the behavior of the microstructure of the materials. The material sintered by MW at $1200{ }^{\circ} \mathrm{C}$ at dwell time of 15 min shown a bulk material. The grain size is smaller in compare with CS. Sol- Gel material by CS indicates that with long dwell times the grain size grows.

With a temperature of $1500^{\circ} \mathrm{C}$ and 2 hours of dwell time, the grain pass from $1.95 \mu \mathrm{m}$ to $2.26 \mu \mathrm{m}$ with 6 hours dwell time. On the other hand, Lyophilized material indicates that with long dwell times the grain size decreases. At the same dwell times, the reduction is from 1.64 to $1.33 \mu \mathrm{m}$. 

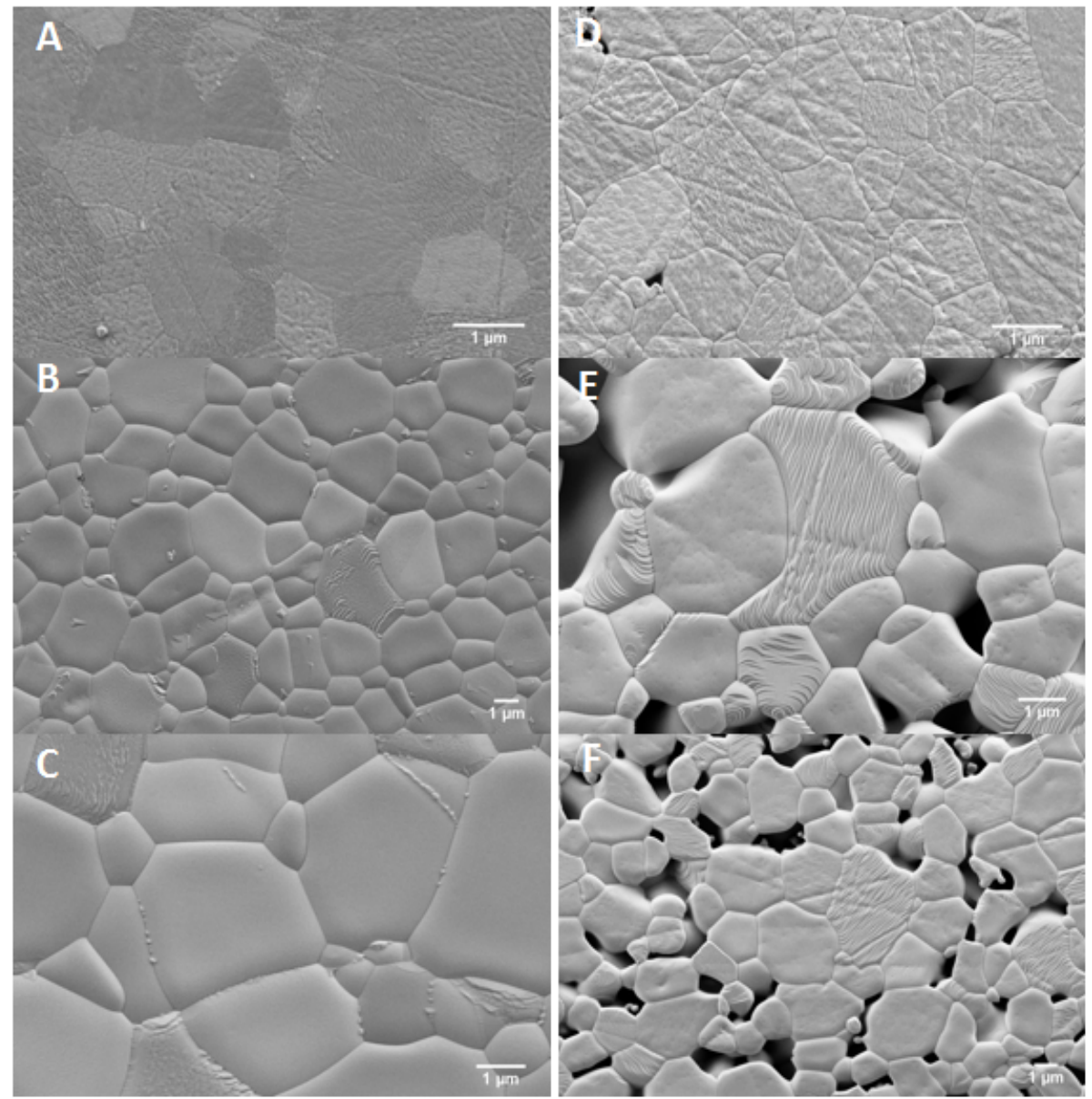

Figure 2. FESEM images of $\mathrm{ZrTiO} 4$ microstructure sintered by $\mathrm{MW}$ and $\mathrm{CS}$. A, B and C corresponds to Sol-Gel material. D, E and F corresponds to Lyophilized material. A and D sintered by MW at $1200{ }^{\circ} \mathrm{C} / 15 \mathrm{~min}$. B and E sintered by CS at $1500{ }^{\circ} \mathrm{C} / 120 \mathrm{~min}$. $\mathrm{C}$ and $\mathrm{F}$ sintered by $\mathrm{CS}$ at $1500{ }^{\circ} \mathrm{C} / 360 \mathrm{~min}$.

\section{Conclusions}

In conclusion, zirconium titanate bulk ceramic material was successfully obtained from SOL-GEL powders and consolidated by MW at temperature of $1200{ }^{\circ} \mathrm{C}$ with a dwell time of 15-min. The density achieved in $\mathrm{ZrTiO}_{4}$ synthetized by sol-gel and sintered by microwave is slightly high in comparison to conventional sintering process (99,7\% versus $98,0 \%)$. The grain size obtained by MW has a measure of $1 \mu \mathrm{m}$. However, the value of grain size treated at different temperatures in CS are double with respect to MW (1,95-2,26 $\mu \mathrm{m})$. Improvement in the hardness value of the material by sintering MW.

The Lyophilized material showed better properties when is exposed at long dwell time. The lyophilized material showed better properties when exposed in a prolonged residence time. In a different way, Sol-gel with more time of permanence its properties decrease. 


\section{Acknowledgements}

The authors would like to thank to the Generalitat Valenciana for financial support received for Santiago Grisolía program scholarship (GRISOLIAP/2018/168). A. Borrell acknowledges the Spanish Ministry of Economy and Competitiveness for her RyC contract (RYC-2016-20915).

\section{References}

[1] Y. Park and Y. Kim, "Influence of cooling rate on the physical properties of tin modified zirconium titanate," J. Mater. Sci. Lett., vol. 15, no. 10, pp. 853-855, 1996.

[2] A. Borrell et al., "ZrTiO4 materials obtained by spark plasma reaction-sintering," Compos. Part B Eng., vol. 56, pp. 330-335, 2013.

[3] A. Borrell and M. D. Salvador, "Advanced ceramic materials: processed and applications," in Advanced ceramic materials: processed and applications, UPV, 2018, pp. 6-9.

[4] A. Borrell, F. L. Penaranda-Foix, M. D. Salvador, J. M. Catala-Civera, and M. Miranda, "Microwave Technique: A Powerful Tool for Sintering Ceramic Materials," Curr. Nanosci., vol. 10, no. 1, pp. 32-35, 2014.

[5] M. Vicent Cabedo, E. Sanchez, I. Santacruz, and R. Moreno, "Dispersion of TiO 2 nanopowders to obtain homogeneous nanostructured granules by spray-drying," $J$. Eur. Ceram. Soc. - J EUR CERAM SOC, vol. 31, pp. 1413-1419, 2011.

[6] A. Borrell, M. D. Salvador, F. L. Peñaranda-Foix, and J. M. Cátala-Civera, "Microwave sintering of Zirconia materials: Mechanical and microstructural properties," Int. J. Appl. Ceram. Technol., vol. 10, no. 2, pp. 313-320, 2013.

[7] ASTM, "ASTM E112-13: Standard test methods for determining average grain size," ASTM Int., pp. 1-28, 2013. 